\title{
Integrating Technology into the Online Classroom Through Collaboration to Increase Student Motivation
}

\author{
Thomas Dyer I Elizabeth Larson I John Steele I Rick Holbeck
}

Technology is one of the most important components in the future of online learning. Instructors in online classes should lead the charge of innovation and integration of technology into the online classroom to ensure that students achieve the best learning outcomes. This article chronicles a theoretical model towards integrating technology as a best practice into the online classroom to increase student motivation, engagement and learning outcomes. Various technologies can be incorporated into the online classroom to enhance the course and meet student needs by offering differentiated instruction and activating various learning styles. This article explains how collaboration among faculty can make this task easier, more efficient and of greater benefit to the online student. It also theorizes that added technological materials equate to increased student engagement, motivation and learning outcomes in a course when a faculty collaboration diagnostic model is followed to integrate technology into the online classroom.

Online education is growing at a rapid pace, which means instructors need to be more innovative to meet these demands (Allen \& Seaman, 2011). Mestre (2010) noted the importance of instructors developing and utilizing online tools to meet the diverse learning needs of today's online learning population. The traditional written lecture method used in some online courses does not meet the needs of the online student population. Research had indicated that there is a vast need for instructors to enhance the online learning environment with several methods, including visual, kinesthetic, textual and auditory delivery methods (Mestre, 2010). This theoretical essay, while qualitative in nature, will discuss the journey of integrating technology into the curriculum of an introductory class by three instructors from a small private university in the Southwest.

\section{BACKGROUND}

In online education today, personalized instruction has become an essential element of an instructor's teaching practices and pedagogy (Popescu, 2010). Popescu's (2010) study found that presenting students with a learning environment that is antagonistic to a student's learning styles can decrease his or her effort, satisfaction and enthusiasm for learning (Popesu, 2010). The argument that is frequently made against online learning is that faculty and students are apt to feel isolated (Power
\& Gould-Morven, 2011). There are many current practices that online instructors can use to create a learning environment that can help increase a student's efforts and satisfaction. One of these practices includes offering more opportunities to participate and activate learning styles through collaboration.

According to Koehler et al. (2013), Michigan State University introduced the first hybrid doctoral program that was highly successful with the majority of the coursework being online. The uni- 
versity experienced a large number of applications, identified many qualified candidates, experienced high retention rates and reported engaging students around the world. The program put a significant emphasis on the considerations of what, where and how things were conveyed to the students. Koehler et al. (2013) noted that there was particular attention paid to integrating state-of-the-art technology and using a range of approaches to convey information. The instructors who participated in Koehler et al.'s research also felt this was the best way to approach integrating technology into the curriculum to reach more learning styles and keep a high level of student engagement. Hence, the Technology Think Tank was instituted to integrate technology into the current curriculum.

\section{PROBLEM STATEMENT}

Instructors in the present study recognized consistently low student outcomes on two particular assignments. Thus, the Technology Think Tank was formed to attempt to create solutions. The individuals involved in the Technology Think Tank brainstormed and discussed ways to improve student outcomes by enhancing the classroom and appealing to various learning styles. The team hoped that added technology would increase student engagement, motivation and outcomes and enhance the learning process. Consequently, the Technology Think Tank decided to develop a 10-step diagnostic model focused on faculty collaboration in order to integrate technology in the classroom among content areas.

\section{SUCCESSFUL COLLABORATION}

Furthermore, the Technology Think Tank thought that the best way to achieve success through integrating technology into the classroom was via collaboration among instructors of the same content. While theories of collaboration are relatively new concerning the disciplines of psychology and education, the group felt that it would be an important piece of these disciplines moving forward in the modern era. Trach (2012) noted that no matter what collaboration model is utilized it must involve relationships, benefits and some sort of outcome. One concept deemed important is commitment among those participating in the collaboration. All instructors within the content area should have the option of participating in the Technology Think
Tank. Faculty who see the benefit of an endeavor will produce greater outcomes. Including those who do not want to be involved may cause problems within the collaboration. The Technology Think Tank determined that the finished product would only be successful if it was beneficial to all stakeholders including the instructors, students and the university as this is the most crucial aspect of successful collaboration.

Gadja and Koliba (2007) explained that collaboration is one major approach that educational policymakers and practitioners are continually trying to improve upon with the focus on student learning. Collaboration was determined to be one of the most crucial elements when integrating technology into the classroom. There are several characteristics that were noted as fundamental to successful intra-organizational collaboration. These necessary characteristics included having a shared purpose, emphasizing a cycle of inquiry, frequent dialogue, decision-making processes, intentional actions and evaluation (Gadja \& Koliba, 2007). Thus, the Technology Think Tank intentionally considered all of these elements when creating the model for collaboration to integrate technology into the online classroom.

Collaboration has become the focal point of many large companies. Miller and Katz (2014) argued that this is because collaboration is increasingly urgent and challenging. Part of the complication with collaboration in today's society is due to increased advances in technology across the globe. The complexities associated with technology can hinder the collaboration process. However, these advances in technology can also allow for effective collaboration that was not possible even a decade ago. Instructors are now able to conduct virtual meetings from almost anywhere around the world and to share their ideas, strategies and even their computer screen with colleagues. This opens up a world of possibilities concerning the collaboration that could take place.

Collaboration was deemed to be of high importance because each individual in the Technology Think Tank embraced distinct approaches, delivered diverse ideas and possessed different individual concerns. Using a collaborative effort ensured each individual would hear the perspectives of others, as well as allow for the sharing of ideas, problems, brainstorming and workload in creating the 
technology. Further, successful collaboration also requires individuals to be personally accountable for his or her contributions. A prosperous group is only as strong as the weakest link, which requires peer accountability. The group found that the collaborative effort also produced greater personal and group success, offered in a safe environment with the exchange of ideas.

\section{STUDENT MOTIVATION}

It is well documented that every student has a distinct learning style that may need to be addressed to reach the highest levels of student achievement (Mestre, 2010). Integrating technology in the classroom allows instructors the opportunity to teach to varying learning styles, which can stimulate student learning and engagement. Technology can convey the concepts of the lesson in an interesting format that appeals to the student while playing to the various learning styles. The intention is that technology will increase the course delivery options, which will lead to improved student outcomes, motivation and engagement. According to Wang, Shannon and Ross (2013), online education offers many options of course delivery even though the students are not physically present. However, it is up to the instructors to find innovative ways to incorporate these new technologies.

Furthermore, offering multiple technological additions to the classroom may increase student engagement and achievement. Mandernach (2009) noted that there is a vast amount of data to substantiate the claim that well-designed multimedia resources can boost student learning outcomes. Technology integration can offer students alternative options supplementary to the reading of texts and other traditional course resources. The integration of technology can help students become more invested and engaged in the classroom by making it more interactive and conducive to a classroom of differing learning styles.

\section{GOALS OF INTEGRATING TECHNOLOGY}

The Technology Think Tank's objective was to target the low achievement areas in the class by adding technology to better assist students with learning the content. The "Technology Think Tank" hoped this would enhance students' perceptions of the experience leading to increased levels of motivation and higher engagement positively resulting in higher achievement. The group was confident that this would increase scores on these assignments while also engaging more students in the lessons through differentiated instruction and teaching to multiple learning styles. The "Technology Think Thank" created a 10-Step Diagnostic Model of Integrating Technology Innovation that outlined the collaboration method used for creating innovative technology. The members hypothesized that by following the 10-Step Diagnostic Model of Integrating Technology Innovation, the faculty would utilize better solutions and technology to enhance their courses.

\section{0-STEP DIAGNOSTIC MODEL OF INTEGRATING TECHNOLOGY INNOVATION}

Accordingly, the Technology Think Tank was initiated to evaluate and improve a first year undergraduate course by offering alternative options employing technology to students on assignments where previous learners had struggled. Formation of this group was the first step in the collaborative process. This was a strictly voluntary group of instructors that were organized by the content lead. The opportunity to join was offered to all instructors teaching the course. There were also many opportunities for faculty teaching the same course to provide input regarding the process. Keeping the opportunity voluntary procured the belief that those who made the choice to participate would be committed to the process. The second step in the collaborative process was to specify the assignments that caused students the most difficulty and/ or what curriculum could be enhanced through technology, which would create the greatest impact on student outcomes. After the first meeting, the Technology Think Tank determined that the primary focus of the group would be improving the logical fallacies assignment and the persuasive writing element in the course. The Technology Think Tank determined that these two objectives extended the greatest difficulty for students and were worth a significant number of points equating to a large percentage of the student's grade in the course. These objectives also precipitated the two major assignments where added technology would be most advantageous.

After the assignments and objectives were targeted, the Technology Think Tank met for step three, which was to brainstorm ideas of technolo- 
gies to incorporate into the classroom. The group analyzed several different ideas and then the next step was for the group to test the strategies. In step four, the group members explored diverse technology applications and Web 2.0 tools. Within this step, the group decided the best approach would be to create a webpage using Weebly, a free website builder that would address the difficult content and concepts in an organized manner while effectively supplementing the existing course materials in an effective way. The famous philosopher Plato once wrote, "Higher order thinking cannot start until the student has mastered conventional wisdom" (Booker, 2007, p. 347). To reach higher orders of thinking, the group felt that the students should be able to master the basic tools in the classroom before using something complex. This was the reasoning behind creating a Weebly page because they are simple to navigate but can provide a wealth of supplemental material in a multi-media format that would address multiple learning styles. Weebly is a Web 2.0 tool that is clear for students to navigate and manageable for instructors to share text, videos and pictures. The Weebly allowed content to be located on one main page with separate tabs displaying specific information, thereby making it easy to access. The website also included analytics regarding the amount of traffic to the website, which the group thought was important as well.

Step five consisted of creating a timeline for creation and implementation. The members of the Technology Think Tank divided the workload evenly among the three instructors. Deadlines were put in place and future meetings were scheduled to ensure that timely progress was made concerning completion of the tasks. Throughout the process, members adhered to strict timelines to ensure prompt completion of the additional resources. Members would also frequently be in communication to gauge the opinions of each other regarding technologies that were created, as well as to assess the content going into them. Each instructor was given editing power to the website to work on his or her piece of the collaboration. Once all pieces were complete, the group came together for step six, which was to edit the new technology pieces for the final revision and discuss how to direct students to these new materials.

According to Schworm and Gruber (2012), there is a lack of help-seeking behaviors from students in online courses that can result in deficiencies in self-regulated learning. Schworm and Gruber (2012) discussed the importance of giving prompts as an instructional method to dilute the impact of inadequate help-seeking behaviors. The team wanted to ensure that the students would be effectively and efficiently directed to these helpful tools and not pass them over, rendering the tools useless. The group made sure to put procedures in place that stressed the importance of these tools and provided the links for easy student access. These procedures included promoting the website in the welcome messages to each student, in the classroom announcements and in a post each week. Developing supplemental materials and resources requires time and commitment. It is important for faculty to be clear and concise in their directions to lead students to the additional resources so that they are effectively used.

Once the group was comfortable with the placement and marketing of additional technology resources, the traffic was monitored for step seven to see how many visitors the resources were capturing. The group members also gauged the feedback from the students to ensure that the material was helpful and easy to use. The group surmised the best way to gauge success was to go directly to the source and identify whether students found the new resources applicable. The feedback from students was positive and the group noticed an improvement in the targeted assignments. Many of these student's comments can be found in the findings section.

During step eight, the group applied the student feedback to assemble adjustments and constantly enhance the material by improving the website. In step nine, the group produced further minor adjustments based on feedback from students and other instructors. The final action, or step 10, was to consider incorporating the material into the curriculum. The material was beneficial for students and was eventually introduced to curriculum and design where it was branded, redeveloped and added into each course of that content. 


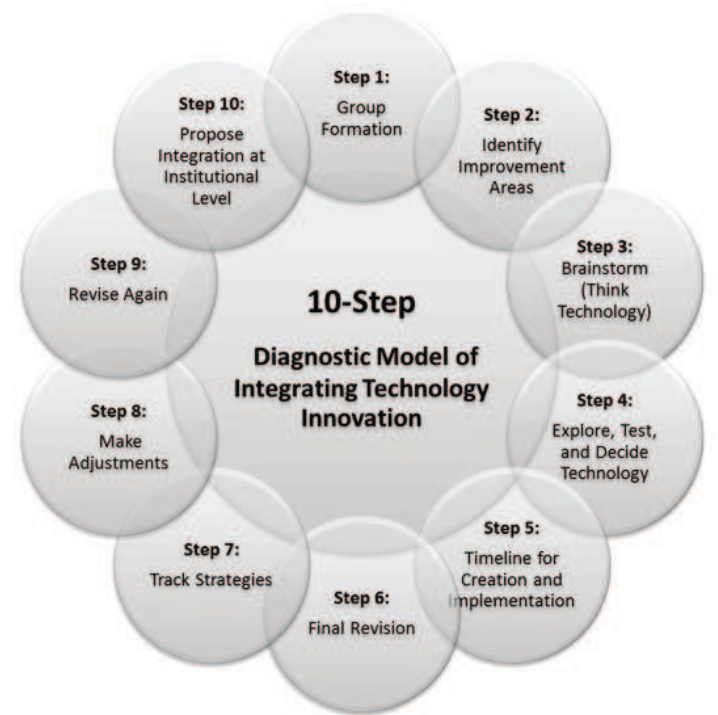

Figure 1. 10-Step Diagnostic Model of Integrating Technology Innovation.

\section{FINDINGS}

The feedback regarding the resources was positive but could not be quantified due to changes to the course and learning management system that made it challenging to track the progress. The technology that was incorporated tracked the amount of traffic to the created website. The website averaged over 100 unique visitors each day and over 200 visitors on a daily basis. Based on the traffic to the website alone, one could arrive at the conclusion that students were at the very least visiting the website. The students proclaimed how the added technology helped them better grasp the concept while also adding an interactive piece to the classroom. The team did notice significant improvements in regards to one assignment identified by the team as the one students struggled with the most. There are many studies regarding the integration of technology into the classroom and intra-organizational collaboration. However, there is little research regarding the combination of the two. The belief is that this paper can be used in part to fill that void in research.

Students were also given an informal frequency scale survey. This survey helped to determine the students' perceptions of the technology integrated into the course and provided a sound base for the strength of the student experience. Students were asked on a scale of 1 to 10 (1 being "not beneficial" and 10 being "very beneficial") how useful the technology integration, specifically the Moovly presentations created by the instructors, were to their personal course success. Students were also asked to comment on whether they would like all of their courses to contain media such as this and why. Students responded with great voracity (emphasis ours):

1. "The videos have helped me a lot. By giving me an overview of what is expected for the new week, it allows me to mentally plan out my week and thus helps me with my time management. I also enjoy the cartoon like characters; they grab and hold my interest. On a scale of 1-10, I definitely give them a 10."

2. "On a scale 1-10, I would rate the videos as a 10. I would love to have the videos available in all of my courses. The videos were beneficial to me in this course. First, I started with reading the text in the chapter followed by then watching the video. Then, I started watching the video, reading the chapter, then watching the video a second time. This way the video gave me information about what the chapter was about and the key points. When I felt I needed a little reinforcement about the text, I would watch the video several times. Watching the video after reading the text was my way to recap the information."

3. "I really liked the media piece presented at the beginning of each module. Since I am both a visual and auditory learner, the summaries of each presentation helped me understand the main objectives of each week. It also directed me on what resources need to be used to fully understand the concepts as well a reminder for assignments due including expectations. On a scale $0-10$ in my opinion the media piece is a $10 . "$

4. "I enjoyed reviewing the videos you provided each week. They feel a bit more personal to me. Hearing an instructor's voice and personality throughout the video keeps me more engaged than just reading chapters. I always find myself retaining new information from the video that I read in the book or lecture but didn't quite stand out. I like having the assignments broken down. It just sounds reassuring to hear the instructor going over the week's work and content in a friendly way. I hope to be able to see these videos as a form on interaction in future classes. I give it a 9." 


\section{DISCUSSION}

The most significant findings involving successful collaboration were the two requirements of commitment and relationships. Faculty that support each other and seek out opportunities to work toward greater student outcomes can benefit from such a model of collaboration. The collaboration was an important piece of the process as each person brought his or her innate skills, abilities, ideas and work ethic to the process. Each individual was able to offer a diverse perspective on the process as well. All three instructors found the collaborative piece to be a valuable part of the process as it helped reduce the overall workload, allowing each person to make contributions based on the individual's skills. For example, one instructor is well versed in technology and able to investigate different designs. Other instructors were particularly strong with other pieces of the content. The group felt that the model that was created would be simple to replicate and would combine the importance of collaboration with integrating technology into the classroom.

The findings were supported with positive student feedback showing that by targeting the low achievement areas with integrated technology the instructors were able to enhance the classroom. The group noticed that many students were more engaged and motivated concerning these assignment topics. The creative outcomes of the group were so successful that instructors with other universities began to use these resources as well. Due to the inability to quantify the results, this exercise would only be deemed as partially supported. The instructors did not have the ability to quantify the improvements in students' achievement due to several confounding variables such as changing learning management systems, course revisions and revisions made to the assignments. However, the added technology was taken and modified into the curriculum at the course level, which would also infer that it was deemed a success by the university.

There were many limitations with the first assignment due to the inability to track any academic progress that was made by students. Several factors contributed to this problem. First, the original assignment was assessed and hand graded by each instructor leaving it viable to subjectivity or grading indifferences. While completing and creating the collaborative diagnostic model for collaboration to integrate technology in the online classroom, the assignment was revised to change the point value, type of the assignment and the way in which it was scored. The assignment changed to a quiz that was computer graded which had been previously hand graded. Another limitation was that the organization changed learning management systems as well. However, instructors did notice improvements in the quality of the second assignment due to more thorough brainstorming prior to writing the essay and more structured and methodically organized thesis statements.

Consequently, the recommendations for future research would be to replicate the collaborative process using the 10-step diagnostic model that was created. Future research could carefully monitor the technology and class results to track how much improvement was made and harness the perceptions of students to gain their perspectives concerning how the added technology enhanced the classroom, motivated the students and ultimately guided them to better results on the assignments. The study could be easily replicated in a traditional environment as well as the online environment. Traditional instructors could collaborate to find innovative ways to create and incorporate the new technology into the traditional classroom as well. The group also theorizes that the 10-step diagnostic model could be very effective for adjunct online faculty as well. As online education continues to develop, the body of research regarding incorporating technology and enhancing the learning experience will continue to grow, thereby providing many opportunities for more original research.

Mandernach (2009) found that students described an elevated degree of engagement when the added supplements were personalized by the instructor instead of coming from a publisher or external professional source. This led the instructors to also include a biography on the website under the about the authors tab on each Weebly to see if this made an impact on students. Students were excited to see that their instructors had created the material. However, future research should investigate the impact of the personalization of technology. 


\section{REFERENCES}

Allen, I. E., \& Seaman, J. (2011). Going the distance: Online education in the United States, 2011. Babson Survey Research Group and Quahog Research Group, LLC. Retrieved from www.onlinelearningsurvey.com/reports/goingthedistance.pdf

Booker, M. J. (2007). A roof without walls: Benjamin Bloom's taxonomy and the misdirection of American education. Academic Questions, 20(4), 347-355.

Gajda, R., \& Koliba, C. (2007). Evaluating the imperative of intraorganizational collaboration: A school improvement perspective. American Journal of Evaluation, 3, 26-44.

Koehler, M., Zellner, A., Roseth, C., Dickson, R., Dickson, W. W., \& Bell, J. (2013). Introducing the first hybrid doctoral program in educational technology. Techtrends: Linking Research \& Practice to Improve Learning, 57(3), 47-53. doi:10.1007/ s11528-013-0662-0

Mandernach, B. J. (2009). Effect of instructor-personalized multi-media in the online classroom. Instructional Review of Research in Open and Distance Learning, 10(3), 1-19.

Mestre, L. S. (2010). Matching up learning styles with learning objects: What's effective? Journal of Library Administration, 50(7/8), 808-829. doi:10.1080/01930826.2010.488975

Milller, F. A., \& Katz, J. H. (2014). 4 keys to accelerating collaboration. OD Practitioner, 46(1), 6-11.

Popescu, E. E. (2010). Adaptation provisioning with respect to learning styles in a Web-based educational system: An experimental study. Journal of Computer Assisted Learning, 26(4), 243-257. doi:10.1111/j.1365-2729.2010.00364.x

Power, M. \& Gould-Morven, A. (2011). Head of gold, feet of clay: The online learning paradox. International Review of Research in Open \& Distance Learning, 12(2), 19-39.

Schworm, S., \& Gruber, H. (2012). e-Learning in universities: Supporting help-seeking processes by instructional prompts. British Journal of Educational Technology, 43(2), 272-281. doi: 10.1111/j.1467-8535.2011.01176x

Trach, J. S. (2012). Degree of collaboration for successful transition outcomes. Journal of Rehabilitation, 78(2), 39-48. Retrieved from http://search.proquest.com/docview/10102810 63 ?accountid $=7374$

Wang, C., Shannon, D. M., \& Ross, M. E. (2013). Students' characteristics, self-regulated learning, technology self-efficacy and course outcomes in online learning. Distance Education, 34(3), 302-323. doi:10.1080/01587919.2013.835779

\section{Author Biographies}

Thomas Dyer is an Assistant Professor at Grand Canyon University. Thomas teaches a number of courses in the College of Humanities and Social Sciences including University Success, Critical Thinking and Psychology. Thomas is a certified elementary teacher and also teaches traditional courses as an adjunct in the College of Education. Thomas has more than six years of experience in higher education and holds a Bachelor of Arts in Elementary Education from Arizona State University, a Master's in Education Administration and a Master's in Psychology from Grand Canyon University. Thomas is currently pursuing his Doctorate degree in General Psychology with an emphasis in integrating Technology, Learning and Psychology. His professional interests include research to examine student engagement and participation in the online learning platform, student motivation, learning and cognition, collaboration, technology integration in the classroom, classroom assessment techniques and academic integrity.

John Steele is an Assistant Professor who teaches Critical Thinking, University Introduction and Psychology classes at Grand Canyon University. $\mathrm{He}$ is a certified K-12 School Counselor, certified elementary teacher and has taught Adjunct Education at Phoenix Community College. He is a GCU Alumnus, with a Master's in Education in School Counseling and a Master's of Science in Psychology. John is currently pursuing his doctoral degree in General Psychology with emphasis in Integrating Technology, Learning and Psychology at GCU. John's professional interests include research in online learning and academic integrity.

Elizabeth Larson has worked in higher education for over eight years and is an Assistant Professor of Online Instruction at Grand Canyon University. She holds Masters Degrees in Secondary Education and Psychology and is pursuing a Doctor of Philosophy in General Psychology with an Emphasis in Industrial and Organizational Psychology. Elizabeth currently serves on the Academic Innovation Board at Grand Canyon University as well as the PHI 105 TEC Committee. Her research interests include cognitive science and the philosophy of technology. 
Rick Holbeck has been in education for 20 years at all levels from kindergarten to higher education. $\mathrm{He}$ is currently Director of Online Full-Time Faculty at Grand Canyon University, and also teaches courses for the College of Education. Rick has presented at several regional, national, and international conferences where the focus has been on Classroom Assessment Techniques, technology, and hybrid peer review for journal publication. He is also currently the Guest Editor for a volume of the Journal of Instructional Research. Rick is currently a doctoral learner in Higher Educational Leadership at Grand Canyon University. 


\title{
Employing Active Learning Strategies to Become the Facilitator, Not the Authoritarian: A Literature Review
}

\author{
Cheryl M. Patton
}

Traditional higher education instruction involves an authoritarian educator who is charged with delivering information in lecture format to passive students. Within the past few decades, a new approach has gained popularity. Active learning allows the students to become more involved in their own learning. The educator becomes more of a facilitator than an authoritarian ruler in the classroom. The purpose of this literature review is to explore the historical underpinnings of active learning, its relevance in pedagogy and contemporary research. Also examined are several active learning strategies that can be utilized in the classroom, including lecturing with pause procedures, the flipped classroom, clickers, peer review and games.

At one time, the idea of the college classroom was uniformity. The educator stood at the front of the room and lectured at his or her students. That instructor was the authority, the all-knowing leader who poured wisdom to the students while they busily took notes. That was then.

The realm of education has changed dramatically over the past few decades. In the 1980s, educators began to look beyond that passive learning strategy and the words active learning were gaining popularity (Berek, 2013). A broad definition for active learning is "anything that involves students doing things and thinking about the things they are doing." (Bonwell \& Wison, 1991, p. 4). Traditionally, homework primarily fulfilled this type of learning (Prince, 2004). Today, in order to improve pedagogy, the traditional educator-centric role of lecturing to students is augmented with active learning strategies in the classroom (Bren, Hilleman, \& Topp, 1998). The purpose of this literature review is to explore empirical research findings on more active learning pedagogies and to share some strategies that educators can use to incorporate more active learning in the classroom.

A literature review is written to accomplish several tasks. The review divulges findings of empirical studies related to the topic of examination. Creswell (2014) notes that it "relates a study to the larger, ongoing dialogue in the literature, filling in gaps and extending prior studies" (p. 28). This literature review includes the underpinnings of the active learning pedagogical style, active learning research findings and the application of active learning in the classroom. 